\title{
Factors Affecting Mobile Learning Acceptance in Higher Education: An Empirical Study
}

\author{
Nahil Abdallah ${ }^{1}$ \\ School of Engineering and \\ Technology, Aldar College \\ University, Dubai, UAE
}

\author{
Odeh Abdallah ${ }^{2}$ \\ Department of Fundamentals \\ Religion, An-Najah National \\ University, Nablus, Palestine
}

\author{
OM Bohra ${ }^{3}$ \\ School of Business Administration, \\ Aldar College University \\ Dubai, UAE
}

\begin{abstract}
The use of mobile tools to support learning and teaching activities has become a significant part of the informal learning process. Mobile learning (M-learning) is used to considerably develop the forms of learning activities made by learners, and support the learning process. The effective application of M-learning in higher educational institutions, however, is based on the learners' adoption. It is therefore essential to define and investigate the factors affecting the desire of learners to use and adopt M-learning. Thus, this research investigates the factors affecting students' intention to adopt $M$ learning in institutions of higher education. To achieve the objectives of this research, a model is proposed based on the Unified Theory of Acceptance and Use of Technology (UTAUT) model and the Technology Acceptance Model (TAM). The instrument is developed using validated items from previous studies and shreds of literature. Data for this quantitative study are collected from undergraduate and postgraduate students. A Structural Equation Model (SEM) is used to analyze the data collected from 218 participants using a survey questionnaire. The findings show that students' intention to adopt M-learning is shaped by various variables consisting of personnel innovativeness, self-management, facilitating conditions, social influence, relative advantage, and effort expectancy. The research results also present several practical contributions and implications for M-learning adoption in terms of research and practice. Investigation of the required determinants may contribute to gain learners' adoption and is important to enhance the learning experience of students and help them improve their knowledge and academic achievement. The contribution of this paper lies in defining the factors influencing the acceptance and use of M-learning systems by students of higher education in Palestine. Hopefully, the results of the study are valuable for policy-makers in designing comprehensive M-learning systems.
\end{abstract}

Keywords-Mobile learning; UTAUT; structural equation modeling; tam; technology acceptance

\section{INTRODUCTION}

Advances in information and communication technology have hugely impacted our daily lives over the previous decades. These developments have recently been recognized as a potential for economic and social developments and competitiveness enhancements. It is also regarded as the most significant probable force in the twenty-first century to develop education. These developments have profoundly affected the techniques of learning and teaching and the governance of the instructional system [1].
There is a growing concern in the learning procedures, alongside innovative technological instruments, such as applied in M-learning [2]. M-learning is prescribed by [3] as the "Learning delivered to students on mobile devices such as Personal Digital Assistants (PDAs), smartphones and mobile phones". Zero technologies have geographically traversed such as mobile phones. Mobile wireless technology has been used in the classroom to improve the quality of learning at different levels and shift the way we live and thus, the way we learn begins to change [4]. Undeniably, cellphones are regarded as the lifeline of the next generation. The extensive accessibility and comparatively low prices of phone devices have strongly opened up new possibilities for leveraging the power and universality of mobile technologies to improve learning and expand instructional possibilities [5]. The rapid advancement of mobile devices and wireless networks within higher educational institutions makes university campuses an appropriate venue to incorporate student-centered M-learning [6]. In the same vein, mobile phones can extend, improve, support, and facilitate learning and teaching activities. As put by [7], innovation in mobile devices enables learners to access instructional emails, portals, library assistants, online data, and project teams. Besides, M-learning improves the flexibility of learning by adjusting learning to be more personalized [8] and helps to access the necessary subject materials in the class regardless of the limitation of time and place [9].

Though M-learning furnishes learners with significant potential capabilities [9], different problems still hinder the use of this technology, alongside other educational matters concerning the acceptance of mobile technology in schools; will this new technology be accepted by users (students and lecturers)? And may they be willing to adopt M-learning [6]. As stated by [9], M-learning success is essentially based on the readiness of learners to embrace a new technology differing from prior styles of learning. Also, [8] has stated that the key success variables of M-learning lean largely on the willingness of learners and their intellectual involvement in mobile activities. Even with the rapid development of M-learning technology, M-learning is still at the initial stages [10]. It has been observed that most of the work on M-learning is initiated in developed countries. However, the notion of mobile education is still a new venue and a rare practice in developing countries [6]. Importantly, there is a lack of empirical research findings on the variables driving the implementation of $\mathrm{M}$ learning $[8,11]$. It should be acquainted that at the initial phase of applying M-learning in higher education institutions, 
students' views of this new technology need to be completely investigated and considered [12]. Thus, it is necessary to carry out research recognizing the necessary aspects of the adoption of M-learning.

In Palestine, M-learning has not been officially embraced in higher education institutions. For instance, the views of university teachers on incorporating mobile technology in their teaching are not taken into account by officials [13]. Despite the fast growth of mobile technologies as a new brand learning platform, the variables influencing M-learning adoption remain uncertain [14]. As asserted by [14], Mobile learning at a tertiary level is still in the beginning stages of implementation globally, and the pedagogy surrounding mobile learning is evolving and requires further pieces of research. A study conducted by [15] has indicated that almost all university students own mobile devices. Therefore, for the effective adoption of M-learning in educational institutions, numerous variables affecting learners' acceptance need to be resolved [16]. Against this, the purpose of this research is to explore the variables influencing the adoption of M-learning by college learners and point out whether the previous experience of using mobile devices impacts the adoption in various higher educational institutions. Further, a model of M-learning acceptance constructed on TAM and UTAUT is used as a theoretical basis. Nevertheless, prior studies suggest that the basic construction of UTAUT may not fully represent the particular impacts of M-learning possibly changing the behavioral intention of a user to use a mobile device [17]. For this reason, this research also examines some additional constructs considered as significant determinants of behavioral intention for M-learning.

This research article is structured as follows: part two presents a review of the literature concerning M-learning systems. Section three presents the research model and hypotheses. A description of the research methodology is given in section four. Section five presents data analysis and results, while section six offers discussion and implications. Section seven concludes this paper.

\section{M-LEARNING}

M-learning, as a rather evolving approach, has been enlightened with diverse descriptions in the literature [18]. It is described by prior research as an alteration of e-learning. Reference [19] has described M-learning as a new tool rapidly advanced to offer E-learning with the use of personal mobile devices. M-learning can be available in any place and at any time, together with traditional teaching settings such as classrooms, workplaces, in transit, and at home, etc [20,21].

M-learning has increasingly become essential as mobile technologies and wireless communications are rapidly developed and accepted by the concerned parties [22]. As reported by [23], M-learning can improve the whole learning procedures and educational experience. The evolution of Mlearning not only delivers education through various settings but also allows students to learn at any time [24]. Villa et al., [25] have stated that mobile devices can improve the way learners cooperate and their behavioral intention towards learning, mostly because they are no longer limited by the constraints of time and space. M-learning also promotes cooperative experiences and relationships with diversities and possibilities beyond the classroom. Therefore, the key issue of M-learning innovation is to propose learning opportunities at anytime and anywhere accomplished using various mobile devices [3]. Even though the decent and the indecent aspects of mobile devices are clear to all, it remains unclear what inspires learners to accept such technology in their learning and whether such usage has a long-term positive impact on the growth of education in general and on students' academic achievement in particular. This is where dedicated models and theories come in to elucidate the technological acceptance phenomenon [26].

\section{RESEARCH MODEL AND HyPOTHESES}

Despite the superb developments related to using information systems and applications, users frequently refuse to adopt such systems. Such resistance leads to financial losses and cases of frustration for organizations due to the low acceptance rates. Hence, low adoption is regarded as the key problem to information technology success implementation [27]. The main success factor for mobile learning understands the factors that lead users to implement their M-learning methods [2]. Over the years, different models and theories have been developed to support researchers in various contexts on the acceptance and use of technology.

The Unified Theory of Acceptance and Use of Technology (UTAUT) [28], and the Technology Acceptance Model (TAM) [29] are regarded as outstanding theoretical models and frameworks aimed at examining individuals' behavioral intentions and usage of Information Systems (IS) and Information Technology (IT). These frameworks have been broadly adopted in numerous IT settings such as education, online banking, shopping, and healthcare informatics [30, 31]. M-learning has its particular unique features, varying from other IS/IT settings [9]. The research, therefore, develops a contextualized model, specifically presented to inspect learners' acceptance of M-learning in higher education institutions in Palestine. The proposed research model (Fig 1) comprises seven variables. Since M-learning is not formally executed in Palestinian educational institutions, the dependent factor of this study model shall be behavioral intention (BI) rather than usage behavior. The independent factors adopted are as follows: effort complexity (EC), relative advantage (RA), social influence (SI), facilitating conditions (FC), Personnel innovativeness (PI), and self-management (SM). Moreover, this research tests the moderating influence of using mobile experience (see Fig 1).

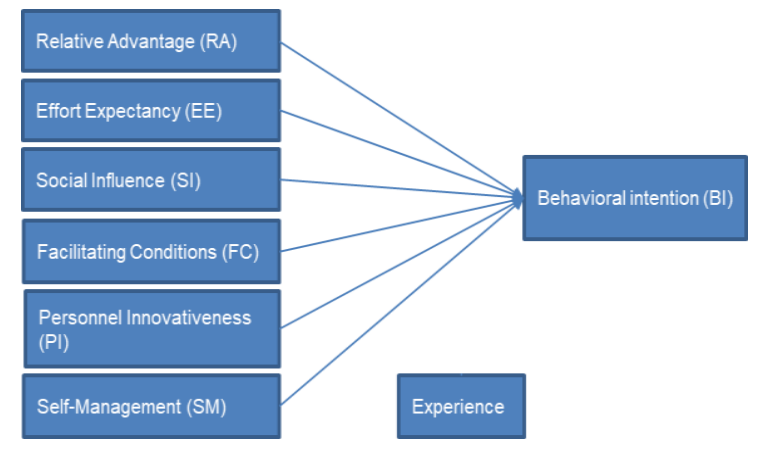

Fig. 1. Research Model. 


\section{A. Relative Advantage (RA)}

Reference [32] has defined relative advantage as "the degree to which a new technology or invention is thought to be more useful than its predecessor". RA is compared to TAM's perceived usefulness construct, and also along the lines of UTAUT's performance expectancy concept. RA has been frequently used by several researchers. If students perceive that it is useful to use M-learning, they will be more likely to accept it [33]. Reference [34] has mentioned that the RA of the Mlearning setting emerges from the unique features of mobile phones compared to traditional learning. With characteristics like connectivity, availability, flexibility, and ubiquity, learners tend to find M-learning helpful as it enables them to use a device of their choice, and smoothly process data without any location and time constraints [9, 12, and 35].

Applying relative advantage to the M-learning setting suggests that learners might find M-learning helpful as they will learn rapidly and conveniently and enhance their learning productivity as well [36]. This empirically verified construct is a robust predictor of technology acceptance, substantially affecting the intention of end-users [4, 37, and 38]. Hence, the proposed hypothesis in this research is:

H1: "PA has a positive effect on behavioral intention to use M-learning".

\section{B. Effort Expectancy (EE)}

Effort expectancy is described by [39] as the level of easiness and efforts required to use the technology. Ease of use and complexity (TAM2) are viewed as the two constructs from prior frameworks that are related to the conception of effort expectancy. Literature shows that M-learning adoption is largely affected by the learning system's ease to use construct $[8,26,40,41]$. M-learning used by learners of higher education should be simple to learn and should take a short time to comprehend [19]. According to [42], if learners regard Mlearning software and hardware as user-friendly, they might be very interested in adopting it in their learning activities. Students will expect the various M-learning activities and procedures to be simple and easy to handle regardless of the limited capabilities of mobile devices. Based on UTAUT, students are anticipated to accept an M-learning depending on whether it can be used easily or not. It is therefore hypothesized that:

H2: "EE has a positive effect on behavioral intention to use M-learning".

\section{Social Influence (SI)}

The social dimension investigates the impact of environmental elements such as other individual's attitudes and social pressure executed on people. Social factors show how people, who are relevant to end-users, influence them toward accepting information technology applications [43]. Subjective norms, voluntariness, and image are grouped under a social dimension to assess the outcomes of others' beliefs on users' decisions to use certain technology [44].

According to [8], the uncertainty level at the early stage in technology adoption is high, where probable users tend to look for optimistic indications of convenient results from social variables. Reference [45] has indicated that students may not be prepared to accept and embrace the new technology unless they are encouraged by other people who could influence their attitude and behavior. Many students are ready to use Mlearning after recommendations from users of the technology such as their peers, workmates, friends, or lecturers [42]. Similarly, Venkatesh et al., [28] have proved that subjective norms had a durable impact on information technology acceptance decisions. Nevertheless, the influence of the subjective norm is reduced over time but is still valuable and significant [17]. Diverse studies have shown that social factor is influential in determining users' adoption of M-learning [4, $8,9,17$, and 46]. It is therefore hypothesized that:

H3: "SI has a positive effect on behavioral intention to use M-learning".

\section{Facilitating Conditions ( FC)}

As an important variable, facilitating conditions are defined by [37] as the extent to which an individual assumes an organizational and technological infrastructure exists to enable the use of a specific technology, particularly, the existing external recourses (effort, money, and time) alongside the technological resources required to enable a certain behavior.

Literature shows that suitable FCs (e.g. training, technical assistance, and adequate assets) are critical to adopt the technology [4, 38, and 47]. Environmental variables are affecting the willingness of an individual to perform the task. Several studies have found numerous complications and technical issues prohibiting students from accepting and using M-learning. Of these complications and technical issues are lack of data input capabilities, unfriendly user interfaces, limited memories, and disk capacities, lack of standardizations, low storages, low bandwidths, small screen sizes, short battery life, lower display resolutions, limited processor speeds, and less surf-ability [48]. Equally, Iqbal and Qureshi [49] have also mentioned that when learners move to M-learning, they face several technical difficulties. [50] has stated that this factor has a positive relationship with the intention to use IT/IS. In this context, the perception of the support provided by technicians' staff and system administrators affects learner satisfaction and the decision to use the system. Therefore, facilitating conditions are found to be an important variable influencing the user's intention and attitude. It is therefore hypothesized that:

$\mathrm{H} 4$ : " $\mathrm{FC}$ has a positive effect on behavioral intention to use M-learning".

\section{E. Personnel Innovativeness (PI)}

PI in the domain of IT is described as an individual's tendency reflecting his or her proclivity to experiment with and adopt new IT regardless of others' communicated experience [51]. Innovative individuals can understand the usefulness and usability of new technology applications more easily than noninnovative individuals. It is noted that people with elevated innovation have a high level of acceptance of new technology. As said by [52], an innovative person takes risks and is capable of dealing with uncertainty.

Al-Busaidi and Al-Shihi [53] have hypothesized and empirically proved that the degree of individual IT innovativeness has a substantial affirmative impact on the 
attitude to accept a particular technology. Similarly, [54] has confirmed that there is a direct relationship between innovativeness and M-technology adoption. Likewise, various researchers have tested personal innovativeness predictor and found that PI has a strong effect on students' intentional behavior to accept M-learning [19, 38, and 52]. Accordingly, the present study hypothesizes that:

H5: "PI has a positive effect on behavioral intention to use M-learning".

\section{F. Self-Management (SM)}

As put by [55], self-management of learning is anticipated to be one of the central issues in the education sector because it plays an important part in promoting successful learning and acts as an indispensable driver of learning performance. Selfmanagement is defined as the degree to which a person believes she or he is self-disciplined and participates in a highly autonomous learning environment [56].

Literature shows that self-management of learning is a significant factor in predicting M-learning acceptance [9, 44, and 57]. A student with high self-directed learning competence prefers accepting and using M-learning [48]. Students sometimes need to manage their education because they are separated from teachers, peers, colleagues, and institutions [17], which in turn requiring students to control their education [11]. Self-management is an important success factor in the development of flexible service, distance, and resource-based learning, namely: M-learning, generating a basic need from students to control their learning [58]. Hence, self-management is considered another important variable to examine university students' attitude to accept M-learning, where the following hypothesis is presented:

H6: "SM has a positive effect on behavioral intention to use M-learning".

\section{RESEARCH METHODOLOGY}

Since the primary purpose of this research is concerned with the M-technology and of students' satisfaction towards M-technology learning, higher education students in Palestinian universities are considered as the unit of analysis. Notably, there is no mandatory requirement for these students to accept M-learning.

A survey instrument was developed to acquire university students' opinions. The questionnaire is divided into two sections: demographic profile of the respondents, and replies concerning the variables that is RA, EE, SI, FC, PI, and SM, and a dependent factor "Behavioral Intention" to use Mlearning. In this research, the sampling method used is stratified random sampling [59]. In this sampling, the population is divided into classes called strata, and randomly selected individuals are drawn from each stratum. This implies that they should reflect the population's heterogeneity while remaining homogeneous among themselves.

There have been numerous proposed rules of thumb for the minimum sample size of structural equation models. The generally recognized representative sample parameter ratio is $\mathrm{N}: \mathrm{p}=5: 1$ [60]. To obtain a reliable estimate, a five-to-one response ratio is expected for each parameter. The appropriate sample size needed to test the model's reliability is 135 with a total of 27 elements. Of all 300 questionnaires distributed to learners, 228 questionnaires have been returned. Of the returned questionnaires, 10 are described as unfinished and hence are excluded. In the end, 218 questionnaires are considered valid for further analysis, giving a response rate of $72.6 \%$. Table 1 shows the characteristics of the respondents. A 5-point Likert scale is used to represent the responses of the subject. A 5-point Likert scale is preferred to enable respondents to answer the questions and understand better what option he/she should select for improving answers' quality.

\section{DATA ANALYSIS AND RESUltS}

For the assessment of the hypothesized causal relations in the proposed research model, choosing the right statistical method is crucial. Structural Equation Modelling (SEM) is a statistical modeling method used to test theoretical or abstract models. Based on reference [61], SEM allows researchers to investigate the interrelationships between multiple variables at the same time. Furthermore, it is a powerful tool that provides sophisticated statistical measures for dealing with complex frameworks.

\section{A. Demographics and Descriptive Statistics}

All the retrieved questionnaires are appropriately entered into the SPSS version 17.0 to conduct the statistical analysis. The respondent demographic profile presented in Table 1 shows that $39 \%$ of the respondents are female and almost $61 \%$ are male. Respondents aged $<20$ years are the largest age group, representing $51.3 \%$ of the sample size. Respondents with more than four years of experience have formed $81.1 \%$ of the sample. To locate outliers and missing values, the data are tested. All the out-coded variables are corrected and the normality of the data is also suitably checked through skewness and kurtosis. Cronbach's Alpha is also used to check data reliability for each construct. Cronbach's alpha ranges from 0 (completely unreliable) to 1 (perfectly reliable). Reference [62] has stated that the closer Cronbach's Alpha to 1.00, the higher the reliability of the measure is. The reliability result is as follows: RA (0.91), EE (0.82), SI (0.90), FC (0.79), PI (0.83), SM (0.84), and BI (0.91). Most metrics have Cronbach's alpha values greater than 0.80 , indicating that they are highly reliable. As a result, there is no need to alter or modify the survey questions to increase the alpha coefficients.

\section{B. Measurement Model}

This research employed a two-phased approach to SEM analysis. First, the measurement model is estimated using CFA to assess the model's validity and reliability. Second, the structural model is used to test hypotheses between constructs. Hypothesized relationships between latent constructs are tested through the assessment of the structural model. To check if the hypothesized structural model and each of the proposed hypotheses have fitted the data, the Goodness-Of-Fit (GOF) indices, alongside the parameter estimates coefficients are examined. The reliability processes are carried out by assessing the reliability of the individual items and the composite reliability of constructs. The significance of individual item loadings is used to determine individual item reliability. The loading of each item on its underlying construct should be $\geqslant$ 
0.707, whereas the composite reliability $(\mathrm{CR})$ should be $\geqslant 0.7$ [63]. The loadings of each of the items on their theoretical constructs are $\geqslant 0.707$ as shown in Table 2. Furthermore, CR values are all $\geqslant 0.7$.

On the other hand, the magnitude and importance of the direction between latent variables and their indicators are used to assess validity. Discriminant validity and convergent validity are used to determine the validity of the construct. According to [63], the perfect convergent validity findings are achieved when standardized loading estimates are 0.7 or higher, AVE estimation is greater than 0.5 , and reliability estimation is greater than 0.7. Having followed the abovementioned suggestions, this study mainly used $0.7>0.5>0.7$ as the minimum cut-off criteria for factor loadings, AVE, and composite reliability in evaluating the convergent validity.

To measure the discriminant validity, AVE for each variable is compared with the corresponding squared interconstruct correlation (SIC). If AVE estimations are found to be consistently larger than SIC estimation, it indicates support for the discriminant validity of the construct. Table 3 shows all preceding conditions achieved by the variables.

TABLE I. DEMOGRAPHIC STATISTICS OF THE RESPONDENTS

\begin{tabular}{|l|l|l|l|}
\hline Measure & Item & Frequency & Percentage (\%) \\
\hline \multirow{2}{*}{ Gender } & Male & 134 & $61.4 \%$ \\
& Female & 84 & $38.6 \%$ \\
\hline \multirow{3}{*}{ Age } & $<20$ & 112 & $51.3 \%$ \\
& $20-24$ & 75 & $34.4 \%$ \\
\hline Experience of S & $>25$ & 41 & $18.8 \%$ \\
Phone & $<3$ Year & 41 & $18.9 \%$ \\
\hline
\end{tabular}

TABLE II. The MEASUREMENT Model ANALysis

\begin{tabular}{|c|c|c|c|c|c|}
\hline Construct & Item & Loading & CR & AVE & ASV \\
\hline $\mathbf{R A}$ & $\begin{array}{l}\text { RA1 } \\
\text { RA2 } \\
\text { RA3 } \\
\text { RA4 }\end{array}$ & $\begin{array}{l}0.86 \\
0.88 \\
0.90 \\
0.83\end{array}$ & 0.92 & 0.63 & 0.063 \\
\hline $\mathbf{E E}$ & $\begin{array}{l}\text { EE1 } \\
\text { EE2 } \\
\text { EE3 } \\
\text { EE4 }\end{array}$ & $\begin{array}{l}0.77 \\
0.82 \\
0.79 \\
0.82\end{array}$ & 0.89 & 0.63 & 0.031 \\
\hline SI & $\begin{array}{l}\text { SI1 } \\
\text { SI2 } \\
\text { SI3 } \\
\text { SI4 }\end{array}$ & $\begin{array}{l}0.82 \\
0.90 \\
0.84 \\
0.85\end{array}$ & 0.93 & 0.59 & 0.098 \\
\hline FC & $\begin{array}{l}\text { FC1 } \\
\text { FC2 } \\
\text { FC3 } \\
\text { FC4 }\end{array}$ & $\begin{array}{l}0.87 \\
0.81 \\
0.92 \\
0.80\end{array}$ & 0.90 & 0.67 & 0.017 \\
\hline PI & $\begin{array}{l}\text { PI1 } \\
\text { PI2 } \\
\text { PI3 }\end{array}$ & $\begin{array}{l}0.90 \\
0.91 \\
0.83\end{array}$ & 0.94 & 0.51 & 0.026 \\
\hline SM & $\begin{array}{l}\text { SM1 } \\
\text { SM2 } \\
\text { SM3 } \\
\text { SM4 }\end{array}$ & $\begin{array}{l}0.88 \\
0.82 \\
0.83 \\
0.87\end{array}$ & 0.93 & 0.68 & 0.012 \\
\hline BI & $\begin{array}{l}\text { BI1 } \\
\text { BI2 } \\
\text { BI3 }\end{array}$ & $\begin{array}{l}0.92 \\
0.91 \\
0.94\end{array}$ & 0.94 & 0.71 & 0.013 \\
\hline
\end{tabular}

TABLE III. DISCRIMINANT VALIDITY ANALYSIS

\begin{tabular}{|l|l|l|l|l|l|l|l|}
\hline & RA & EE & SI & FC & PI & SM & BI \\
\hline RA & $\mathbf{0 . 8 8}$ & & & & & & \\
\hline EE & 0.06 & $\mathbf{0 . 7 2}$ & & & & & \\
\hline SI & 0.03 & 0.08 & $\mathbf{0 . 9 2}$ & & & & \\
\hline FC & 0.02 & 0.02 & 0.01 & $\mathbf{0 . 8 1}$ & & & \\
\hline PI & 0.02 & 0.02 & 0.09 & 0.17 & $\mathbf{0 . 8 7}$ & & \\
\hline SM & 0.06 & 0.08 & 0.11 & 0.1 & 0.07 & $\mathbf{0 . 8 9}$ & \\
\hline BI & 0.04 & 0.13 & 0.04 & 0.11 & 0.41 & 0.09 & $\mathbf{0 . 7 7}$ \\
\hline
\end{tabular}

\section{Structural Model}

Table 4 indicates the structural model fit indices defining how well the presented model fits the collected data. The proposed structural model in this research is found to be valid.

Coefficient parameter estimates are another significant component of the structural model assessment. The path significance of each relationship is analyzed to test research hypotheses, and the estimated population covariance matrix for the structural model is calculated using parameter estimates. Critical ratios, standardized estimates, and the p-value are used correctly to examine the hypotheses of this study.

When the critical ratio (CR or t-value) is greater than 1.96, it is presumed that the correlation is statistically significant at the 0.05 level [63]. Based on the path estimates and CR, all of the casual paths in the model are examined. The path analysis for all the variables "RA $(\beta=0.17)$, $E E(\beta=0.20)$, SI $(\beta=0.23)$, FC $(\beta=0.15)$, PI $(\beta=0.13)$, and SM $(\beta=0.14)$ " has significant positive effects on BI, and therefore they are operated as key variables assisting the acceptance of M-learning. Thus, all hypotheses are supported.

\section{Influences of Moderator Variable}

To identify the moderating effect of the mobile experience variable, the study sample is divided into two groups: less than three years of experience, and more than three years of experience in using smartphones. Having established a sufficient model fit for both groups, multi-group analysis is employed. The t-test approach [64] is considered to identify the significant differences among path coefficients (Table 5). The results also show that the structural weights for group 1 (3 years or less) are statistically significant for all $(\mathrm{P}<0.05)$. The structural loading values are $0.25,0.40,0.27,0.22,0.26$, and 0.25 , respectively. Similarly, the structural weights for group 2 (more than 3 years) are also statistically significant for all $(\mathrm{P}<$ $0.05)$. The structural loading values are $0.33,0.34,0.26,0.35$, 0.23 , and 0.25 , respectively.

TABLE IV. STRUCTURAL MOdEL Fít Indíces

\begin{tabular}{|l|l|l|l|l|l|l|l|}
\hline $\begin{array}{l}\text { Model Fit } \\
\text { Indices }\end{array}$ & $\begin{array}{l}\boldsymbol{\chi 2} / \mathbf{d} . \\
\mathbf{f}\end{array}$ & GFI & $\begin{array}{l}\text { AGF } \\
\mathbf{I}\end{array}$ & NFI & CFI & TLI & $\begin{array}{l}\text { RMSE } \\
\text { A }\end{array}$ \\
\hline $\begin{array}{l}\text { Recommende } \\
\text { d value }\end{array}$ & $\begin{array}{l}\leq 3.0 \\
0\end{array}$ & $\begin{array}{l}\geq 0.9 \\
0\end{array}$ & $\geq 0.8$ & $\geq 0.9$ & $\geq 0.9$ & $\geq 0.9$ & $\leq 0.08$ \\
\hline obtained & 1.11 & $\begin{array}{l}0.92 \\
0\end{array}$ & 0.862 & $\begin{array}{l}0.90 \\
1\end{array}$ & $\begin{array}{l}0.99 \\
8\end{array}$ & $\begin{array}{l}0.99 \\
1\end{array}$ & 0.036 \\
\hline \multicolumn{7}{|l}{ Hair et al., [63]. } \\
\hline
\end{tabular}


TABLE V. MODERATING EFFECTS

\begin{tabular}{|l|l|l|l|l|l|l|}
\hline \multicolumn{3}{|c|}{} & \multicolumn{3}{|c|}{$\mathbf{3}$ years or less n $=41$} & \multicolumn{3}{l|}{ More than 3 years n $=177$} \\
\cline { 2 - 7 } & Estimate & $t$-value & $P$ & Estimate & $t$-value & $P$ \\
\hline $\begin{array}{l}\text { RA } \rightarrow \\
\text { BI }\end{array}$ & 0.25 & 2.80 & 0.01 & 0.33 & 2.83 & 0.01 \\
\hline $\begin{array}{l}\text { EE } \rightarrow \\
\text { BI }\end{array}$ & 0.40 & 4.37 & 0.00 & 0.34 & 2.79 & 0.01 \\
\hline $\begin{array}{l}\text { SI } \rightarrow \\
\text { BI }\end{array}$ & 0.27 & 3.08 & 0.00 & 0.26 & 1.83 & 0.05 \\
\hline $\begin{array}{l}\text { FC } \rightarrow \\
\text { BI }\end{array}$ & 0.22 & 2.37 & 0.02 & 0.35 & 2.83 & 0.01 \\
\hline $\begin{array}{l}\text { PI } \rightarrow \\
\text { BI }\end{array}$ & 0.26 & 2.83 & 0.01 & 0.23 & 1.33 & 0.05 \\
\hline $\begin{array}{l}\text { SM } \rightarrow \\
\text { BI }\end{array}$ & 0.25 & 2.33 & 0.01 & 0.25 & 1.93 & 0.01 \\
\hline
\end{tabular}

\section{DISCUSSION AND IMPLICATIONS}

The findings show that the proposed model sufficiently predicts the students' behavioral intention to adopt M-learning. The results also demonstrate that relative advantage has a substantial optimistic impact on M-learning. The empirical results support the argument that the relative advantage of Mlearning has a positive influence on the students' intention to adopt and accept M-learning. In a related sense of M-learning acceptance, empirical studies [6,9, and 17] have found that relative advantage has a major effect on mobile use. These empirical results indicate that students are compelled to embrace and follow M-learning because of pre-existing beliefs based on a perceived relative advantage after considering its utility. As a result, if the utility of M-learning is recognized by potential users, it is more possible to be adopted on a large scale by students in different colleges with various academic majors.

In agreement with [7] and [48], effort complexity is considered a crucial enabler of M-learning adoption. The hypothesized relationship between EE and PI tested through hypothesis $\mathrm{H} 2$ (i.e. EE $\rightarrow$ PI) is found to be significant. Therefore, based on the parameter estimate results $(\beta=0.20, \mathrm{t}-$ value $=4.37, \mathrm{p}=0.001$ ), the proposed research hypothesis is supported. A researcher like [52] has also argued that EE primarily influences the students' usage intention. In line with the findings of previous research, statistical analysis of this study reveals that EE is a strong predictor of PI and an increase in students' perception that the easiness of M-learning would further enhance its capability toward the enhancement of education. The easier M-learning is perceived by students, the more likely it is to be used. Nevertheless, M-learning designers shall take into consideration the need for spontaneous and userfriendly interfaces.

People are more likely to engage in a certain action when they have a good outlook toward it and feel that important people think they should. M-learning behavioral intention to use is thought to be influenced by subjective norms. However, the results of parameter estimates $(\beta=0.23$, t-value $=3.08)$ indicate a significant relationship between SI and PI. Therefore, this hypothesis is supported. These findings suggest that SI is a direct fundamental determinant of M-learning acceptance. Many previous studies have shown empirical pieces of evidence of the direct impact of SI over PI in a similar domain and supported the studies' findings $[4,19,38$, 44, and 49]. Based on this conclusion, teachers should encourage and assist learners to achieve the advantages of Mlearning.

Similarly, hypothesis $\mathrm{H} 4$ (FC $\rightarrow \mathrm{AU})$ suggesting "FC has a positive effect on behavioral intention to use M-learning" shows a significant result. Parameter estimate results $(\beta=$ 0.15 , $\mathrm{t}$-value $=2.37$ ) indicate that this hypothesis is found to be statistically significant at $\mathrm{p}=0.001$ level. Therefore, these results demonstrate that the students' belief to adopt M-learning is directly influenced by the availability of facilitating conditions. Compatible with the results of this study, many researchers [9, 17, 44, 48, and 49] also show a direct significant relationship between FC and PI. Therefore, Mlearning suppliers should provide technical assistance and training for learners to encourage their interaction with $\mathrm{M}$ learning applications. M-learning suppliers must also make sure free and sufficient wireless networks are available in universities.

Supported by [38], [52], [26], and [6], the findings also propose that the variable of Personnel innovativeness is a substantial enabler of M-learning acceptance. A student with strong personal innovativeness is ready to take risks and try the innovation. Meaning that, in the early stages of M-learning, an efficient approach to motivate learners with high innovations shall be considered, as it has a beneficial effect on expected achievements and performance expectancy [6].

Finally, Consistent with [7, 9, 11, and 48], the findings of this study show that students' intention to use M-learning is significantly influenced by their ability to control their learning. Such a finding suggests that learners with highly independent learning skills are more interested in using Mlearning than learners with low self-learning skills. Besides, instructors should conscientiously deliver learning materials to support students' habit of constant self-learning and lifelong learning.

With regards to the moderating students' experience variable in using mobile, the findings show that there are important differences with regards to the impacts of this variable on students' behavioral intention to adopt the technology. Learners' experience of smartphone technology moderates the effects of the various variables on behavioral intention. Of all these factors, the social dimension factor was the strongest element of user intention. Therefore, friends and colleagues play a major role in encouraging other learners to adopt and use M-learning. Exactly, early users of M-learning could be used as an efficient means to persuade other learners to accept M-learning.

By combining the research results and mobile information systems from the perception of education literature, this study shows learners' attitudes and ability to use mobile learning in higher education in a systematic way. Although there are several pieces of research exploring the M-learning adoption in many countries, the author argues that there is a current lack of published studies examining the UTAUT2 model in Palestine. 
The full potential of M-learning is unlikely to be realized without significant and first-degree M-learning adoption. In this setting, the findings of this study have pushed the boundaries of knowledge in the field of M-learning adoption by making an important impact on the literature review. This research also made a significant contribution to the theoretical concept of M-learning by understanding the factors affecting behavioral intentions to use M-learning and developing a simplified conceptual model that is used as a frame of reference by researchers, policymakers, and other higher educational institutions. At last, to successfully provide Mlearning, it is always necessary to understand the factors boosting and preventing learning of such technology. The findings of this empirical research study add to the current literature on technology acceptance and introduce a novel framework for understanding and explaining key factors influencing students' acceptance of M-learning. The study model likewise launches a new foundational framework that can be evaluated by concerned administrators and educators to assess success variables for adopting M-learning.

\section{CONCLUSION}

In a nutshell, understanding users' views are significant in the process of presenting new technologies. Based on the UTAUT and TAM models, this research suggests a model exploring the variables that influence the intention of university students to adopt M-learning in developing countries such as Palestine. The research model provides the means to understand what variables control students' behavioral intention to use M-learning and how that could influence future uses. The results of this research make an indispensable contribution to M-learning literature with empirical findings from a least developed country. Additionally, the result of this empirical research is hoped to help policymakers and administrators who are willing to adopt M-learning in similar contexts.

Like any other studies, this research has some constraints and limitations. Only students from two colleges have participated in this research. More public and private colleges should be included in future research to expand the sample population. Furthermore, since this study used a survey questionnaire as a research tool, potential studies using a blended approach should be considered to provide a more comprehensive understanding of M-learning implementation. Lastly, university instructors are the main backbone for accepting any new technology; their role has been largely neglected as main players for adopting M-learning. Future studies are required to test instructors' views of M-learning and demonstrate which difficulties they may expose when adopting M-learning in the teaching process.

\section{REFERENCES}

[1] S. Papadakis and M. Kalogiannakis, "A Research Synthesis of the Real Value of Self-Proclaimed Mobile Educational Applications for Young Children," in Mobile Learning Applications in Early Childhood Education, ed: IGI Global, 2020, pp. 1-19.

[2] L. Díez-Echavarría, A. Valencia, and L. Cadavid, "Mobile learning on higher educational institutions: how to encourage it?. Simulation approach," Dyna, vol. 85, pp. 325-333, 2018.
[3] M. Sarrab, "M-learning in education: Omani Undergraduate students perspective," Procedia-Social and Behavioral Sciences, vol. 176, pp. 834-839, 2015.

[4] M. S. Ahmed and A. Kabir, "The Acceptance of Smartphone as a Mobile Learning Tool: Students of Business Studies in Bangladesh," Malaysian Online Journal of Educational Technology, vol. 6, pp. 38-47, 2018.

[5] S. Iqbal and Z. A. Bhatti, "An investigation of university student readiness towards M-learning using technology acceptance model," The International Review of Research in Open and Distributed Learning, vol. 16,2015

[6] A. Abu-Al-Aish and S. Love, "Factors influencing students' acceptance of M-learning: An investigation in higher education," The International Review of Research in Open and Distributed Learning, vol. 14, 2013.

[7] Y. F. Chye, J. C. Ong, J. X. Tan, and S. J. Thum, "The fundamental factors that influencing mobile learning acceptance in higher education institution," UTAR, 2014.

[8] M. Sarrab, I. Al Shibli, and N. Badursha, "An empirical study of factors driving the adoption of mobile learning in Omani higher education," The International Review of Research in Open and Distributed Learning, vol. 17, 2016.

[9] A. S. Al-Adwan, A. Al-Madadha, and Z. Zvirzdinaite, "Modeling students' readiness to adopt mobile learning in higher education: An empirical study," International Review of Research in Open and Distributed Learning, vol. 19, 2018.

[10] A. Lu, Q. Chen, Y. Zhang, and T. Chang, "Investigating the Determinants of Mobile Learning Acceptance in Higher Education Based on UTAUT," in 2016 International Computer Symposium (ICS), 2016, pp. 651-655.

[11] Al-Adwan, A. Samed, Al-Adwan, Berger, and Hilary, "Solving the mystery of mobile learning adoption in higher education," International Journal of Mobile Communications, vol. 16, pp. 24-49, 2018.

[12] J. R. Batmetan and V. R. Palilingan, "Higher education students' behaviour to adopt mobile learning," in IOP Conference Series: Materials Science and Engineering, 2018, p. 012067.

[13] K. Shraim and H. Crompton, "Perceptions of Using Smart Mobile Devices in Higher Education Teaching: A Case Study from Palestine," Contemporary Educational Technology, vol. 6, pp. 301-318, 2015.

[14] S. I. Senaratne and S. M. Samarasinghe, "Factors Affecting the Intention to Adopt M-learning," International Business Research, vol. 12, pp. 150164, 2019.

[15] A. Z. Shaqour, "Students' Readiness towards M-learning: A Case Study of Pre-Service Teachers in Palestine," Journal of Educational and Social Research, vol. 4, p. 19, 2014.

[16] T. Thomas, L. Singh, and K. Gaffar, "The utility of the UTAUT model in explaining mobile learning adoption in higher education in Guyana," International Journal of Education and Development using ICT, vol. 9, 2013.

[17] N. G. Uğur, T. Koç, and M. Koç, "An analysis of mobile learning acceptance by college students," Journal of educational and instructional studies in the world, vol. 6, pp. 1-11, 2016.

[18] H. Akour, "Determinants of mobile learning acceptance: an empirical investigation in higher education," Oklahoma State University, 2009.

[19] Y. S. Poong, S. Yamaguchi, and J.-i. Takada, "Investigating the drivers of mobile learning acceptance among young adults in the World Heritage town of Luang Prabang, Laos," Information Development, vol. 33, pp. 57-71, 2017.

[20] R. Petley, J. Attewell, and C. Savill-Smith, "Not just playing around: the MoLeNET experience of using games technologies to support teaching and learning," in Wireless Technologies: Concepts, Methodologies, Tools and Applications, ed: IGI Global, 2012, pp. 1429-1442.

[21] M. Kalogiannakis and S. Papadakis, "Evaluating pre-service kindergarten teachers' intention to adopt and use tablets into teaching practice for natural sciences," International Journal of Mobile Learning and Organisation, vol. 13, pp. 113-127, 2019.

[22] M. A. Embi and N. M. Nordin, "Mobile learning: Malaysian initiatives and research findings," Malaysia: Centre for Academic Advancement, Universiti Kebangsaan Malaysia, pp. 1-131, 2013. 
[23] B. Oberer and A. Erkollar, "Mobile learning in higher education: a marketing course design project in Austria," Procedia-Social and Behavioral Sciences, vol. 93, pp. 2125-2129, 2013.

[24] G. W.-H. Tan, K.-B. Ooi, L.-Y. Leong, and B. Lin, "Predicting the drivers of behavioral intention to use mobile learning: A hybrid SEMNeural Networks approach," Computers in Human Behavior, vol. 36, pp. 198-213, 2014.

[25] E. Villa, L. Ruiz, A. Valencia, and E. Picón, "Electronic commerce: factors involved in its adoption from a bibliometric analysis," Journal of theoretical and applied electronic commerce research, vol. 13, pp. 39-70, 2018.

[26] R. Vrana, "Acceptance of mobile technologies and M-learning in higher education learning: an explorative study at the Faculty of Humanities and Social Science at the University of Zagreb," in 2018 41st International Convention on Information and Communication Technology, Electronics and Microelectronics (MIPRO), 2018, pp. 0738-0743.

[27] M. S. Abbasi, A. Tarhini, M. Hassouna, and F. Shah, "SOCIAL, ORGANIZATIONAL, DEMOGRAPHY AND INDIVIDUALS'TECHNOLOGY ACCEPTANCE BEHAVIOUR: A CONCEPTUAL MODEL," European Scientific Journal, ESJ, vol. 11, 2015.

[28] V. Venkatesh, M. G. Morris, G. B. Davis, and F. D. Davis, "User acceptance of information technology: Toward a unified view," MIS quarterly, pp. 425-478, 2003.

[29] F. D. Davis, "Perceived usefulness, perceived ease of use, and user acceptance of information technology," MIS quarterly, pp. 319-340, 1989.

[30] H. Celik, "Customer online shopping anxiety within the Unified Theory of Acceptance and Use Technology (UTAUT) framework," Asia Pacific Journal of Marketing and Logistics, vol. 28, pp. 278-307, 2016.

[31] M. AlKailani, "Factors Affecting the Adoption of Internet Banking in Jordan: An Extended TAM Model," Journal of Marketing Development \& Competitiveness, vol. 10, 2016.

[32] E. Roggers, "Complex adaptive systems and the diffusion of innovation," The Innovation Journal: The Public Sector Innovation Journal, vol. 10, 2005.

[33] G. Jackman, "Investigating the factors influencing students' accepting mobile learning: the cave hill campus experience," Caribbean Educational Research Journal, vol. 2, p. 14.32, 2014.

[34] I. Arpaci, "A comparative study of the effects of cultural differences on the adoption of mobile learning," British Journal of Educational Technology, vol. 46, pp. 699-712, 2015.

[35] B. Klimova, "Impact of Mobile Learning on Students' Achievement Results," Education Sciences, vol. 9, p. 90, 2019.

[36] Y. S. Wang, M. C. Wu, and H. Y. Wang, "Investigating the determinants and age and gender differences in the acceptance of mobile learning," British journal of educational technology, vol. 40, pp. 92-118, 2009.

[37] V. Venkatesh, J. Y. Thong, and X. Xu, "Consumer acceptance and use of information technology: extending the unified theory of acceptance and use of technology," MIS quarterly, vol. 36, pp. 157-178, 2012.

[38] A. A. Arain, Z. HUSSAIN, M. VIGHIO, and W. RIZVI, "Factors Influencing Acceptance of Mobile Learning by Higher Education Students in Pakistan," Sindh University Research Journal-SURJ (Science Series), vol. 50, pp. 141-146, 2018.

[39] V. Venkatesh, J. Y. Thong, and X. Xu, "Consumer acceptance and use of information technology: extending the unified theory of acceptance and use of technology," MIS quarterly, pp. 157-178, 2012.

[40] F. Ozdamli and H. Uzunboylu, "M-learning adequacy and perceptions of students and teachers in secondary schools," British Journal of Educational Technology, vol. 46, pp. 159-172, 2015.

[41] M. Alnabhan and Y. Aljaraideh, "Collaborative M-learning Adoption Model: A Case Study for Jordan," International Journal of Emerging Technologies in Learning (iJET), vol. 9, pp. 4-10, 2014.

[42] J. Mtebe and R. Raisamo, "Investigating students' behavioural intention to adopt and use mobile learning in higher education in East Africa," International Journal of Education and Development using ICT, vol. 10, 2014.
[43] L. Rashotte, "Social influence," The Blackwell encyclopedia of sociology, 2007.

[44] L. Aofan, C. Qianqian, Y. Zhang, and T. Chang, "Investigating the Determinants of Mobile Learning Acceptance in Higher Education Based on UTAUT," in International Computer Symposium, Chiayi, Taiwan, 2016.

[45] A. A. Taiwo and A. G. Downe, "The theory of user acceptance and use of technology (UTAUT): A meta-analytic review of empirical findings," Journal of Theoretical \& Applied Information Technology, vol. 49, 2013.

[46] M. Rehman, M. Anjum, F. Askri, M. Kamran, and V. Esichaikul, "Mobile learning adoption framework: An empirical investigation from learners perspective," Journal of Quality and Technology Management, vol. 12, pp. 1-43, 2016.

[47] A. Aypay, H. C. Celik, A. Aypay, and M. Sever, "Technology Acceptance in Education: A Study of Pre-Service Teachers in Turkey," Turkish Online Journal of Educational Technology-TOJET, vol. 11, pp. 264-272, 2012

[48] Y. Huan, X. Li, M. Aydeniz, and T. Wyatt, "Mobile learning adoption: An empirical investigation for engineering education," International Journal of Engineering Education, vol. 31, pp. 1081-1091, 2015.

[49] S. Iqbal and I. A. Qureshi, "M-learning adoption: A perspective from a developing country," The International Review of Research in Open and Distributed Learning, vol. 13, pp. 147-164, 2012.

[50] M. Abbad, "Proposed model of e-learning acceptance," in International Conference on Education and e-Learning Innovations, 2012, pp. 1-9.

[51] N. Schillewaert, M. J. Ahearne, R. T. Frambach, and R. K. Moenaert, "The adoption of information technology in the sales force," Industrial Marketing Management, vol. 34, pp. 323-336, 2005.

[52] A. Bombaes, "Student's Intentions to Use M-learning: An Empirical Perspective from the Philippines," Business and Economic Research, vol. 8, pp. 68-83, 2018.

[53] K. A. Al-Busaidi and H. Al-Shihi, "Instructors' acceptance of learning management systems: A theoretical framework," Communications of the IBIMA, vol. 2010, pp. 1-10, 2010.

[54] C.-H. Liu and Y.-M. Huang, "An empirical investigation of computer simulation technology acceptance to explore the factors that affect user intention," Universal Access in the Information Society, vol. 14, pp. 449-457, 2015.

[55] R.-T. Huang, "Exploring the moderating role of self-management of learning in mobile English learning," 2014.

[56] P. J. Smith, K. L. Murphy, and S. E. Mahoney, "Towards identifying factors underlying readiness for online learning: An exploratory study," Distance education, vol. 24, pp. 57-67, 2003.

[57] J. N. Lowenthal, "Using mobile learning: Determinates impacting behavioral intention," The Amer. Jrnl. of Distance Education, vol. 24, pp. 195-206, 2010.

[58] S. Yang, "Understanding undergraduate students' adoption of mobile learning model: A perspective of the extended UTAUT2," Journal of convergence information technology, vol. 8, p. 969, 2013.

[59] G. Kalton and K. Graham, Introduction to survey sampling vol. 35: Sage, 1983.

[60] R. B. Kline, Principles and practice of structural equation modeling: Guilford publications, 2015

[61] J. F. Hair, W. C. Black, B. J. Babin, R. E. Anderson, and R. L. Tatham, "Multivariate data analysis (Vol. 6): Pearson Prentice Hall Upper Saddle River," ed: NJ, 2006.

[62] U. Sekaran and R. Bougie, Research methods for business: A skill building approach: John Wiley \& Sons, 2016.

[63] J. F. Hair, W. C. Black, B. J. Babin, R. E. Anderson, and R. L. Tatham, Multivariate data analysis vol. 6: Pearson Prentice Hall Upper Saddle River, NJ, 2006.

[64] J. F. Hair, M. Sarstedt, C. M. Ringle, and J. A. Mena, "An assessment of the use of partial least squares structural equation modeling in marketing research," Journal of the academy of marketing science, vol. 40, pp. 414433, 2012. 